\title{
A Hubbert Analysis on Natural Gas Production of the Top Producers. How the Carbon Budget Is Affected Under Unconstrained Extraction
}

\author{
Karvounis Panagiotis ${ }^{1}$, Martin J. Blunt ${ }^{2}$ \\ ${ }^{1}$ Politecnico di Milano, Department of Energy \\ Via Lambruschini Milano, Italy \\ panagiotis.karvounis@mail.polimi.it \\ ${ }^{2}$ Imperial College London, Department of Earth Science and Engineering \\ SW7 2AZ, United Kingdom
}

\begin{abstract}
The Hubbert curve was first introduced seventy years ago, to estimate oil reserves and production in the US. In this paper, Hubbert's logistic function is used to estimate the peak production of natural gas of the top producers worldwide. The aim is to manage and fit the historic data with the minimum error and eventually project the $\mathrm{CO}_{2}$ emissions that result if the estimated reserves are extracted. Finally, we try to answer how the carbon budget is affected if production continues unconstrained. To that extend, historic data of the major producers were fitted and both production and expected emissions, were estimated. For several countries, the logistic function presented an adequate fit, while for others, it did not. The countries that didn't fall under the bell-shaped (Hubbert) curve, have made political decisions to constrain their production. Continuing with the other countries (so called reference countries) we estimate that their cumulative emissions from natural gas production, will account for 59\% of worldwide emissions by 2050 , with China and the US dominating. Most importantly, in the case of no action for mitigating the emissions, total $\mathrm{CO}_{2}$ emitted, from natural gas production only, will consume $85 \%$ of the available carbon budget by 2050 to limit expected temperature increases to $1.5{ }^{\circ} \mathrm{C}$ and $31 \%$ of the budget in the case of a $2{ }^{\circ} \mathrm{C}$ temperature increase.
\end{abstract}

Keywords: Hubbert curve, logistic function, natural gas production, $\mathrm{CO}_{2}$ emissions, carbon budget

\section{Introduction}

In 2018 global production of natural gas has risen to almost 4000 billion cubic meters, corresponding to a $4 \%$ growth based on 2017. Production has been increasing at a rate of $2.8 \%$ per year since the global economic recession of 2009, according to the IEA (International Energy Agency) [1]. Within the OECD (Organization for Economic Cooperation and Development), the United States, continues to dominate production, with Canada and Norway following. The greatest decline was observed in the Netherlands due to restrictions on their major Groningen field [2]. Demand has also increased in developing states due to growth in their economies. Compared to other fossil fuels, natural gas has lower carbon intensity and presents higher efficiency in power production. Therefore, it is considered a major alternative to coal and oil in the transition to a low-carbon economy that still dominates in the power sector in many countries [3].

In 2015 at the 21st Conference of Parties (COP21) unanimously all the involved nations undertook major steps to combat climate change and limit global temperature increases to "well below $2{ }^{\circ} \mathrm{C}$ " compared to pre-industrial levels [4]. The countries agreed that climate change mitigation would account for more than $80 \%$ of global GHG emissions. To stall the temperature, increase below the threshold of $2{ }^{\circ} \mathrm{C}$ a limit has been set in the amount of $\mathrm{CO}_{2}$ to be emitted by 2100 , referred

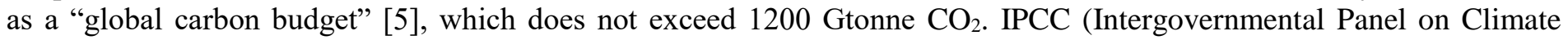
Change) has identified certain measures, essential to enable us to stay within the available carbon budget, which include among others, increases in energy efficiency, employment of renewable energy sources in the power sector, carbon capture and storage technologies, and reduced dependency on fossil fuels [6], [7]. Natural gas has an important role in this effort, cannot be produced unconstrained while still meeting the carbon budget. There is a great debate among the scientific community on the effect of natural gas production and consumption on climate change. Several studies $[8,9]$ indicate that coal substitution with natural gas will reduce $\mathrm{CO}_{2}$ emissions. Others argue that non- $\mathrm{CO}_{2}$ associated emissions from shale gas, make life cycle emissions greater than those of coal [10]. A comprehensive study of five leading integrated assessment models, estimates that moving energy production systems to natural gas is not necessary an effective climate change mitigation measure [11], [14]. 
The aim of this study is to employ Hubbert's logistic function to estimate the future production of certain nations that are among the greatest producers of natural gas worldwide. This projection is only feasible and accurate, if the historical data provided in literature, are fitted adequately. After estimating the production projections and applying the essential emission factors for natural gas, the calculation of $\mathrm{CO}_{2}$ emissions, if this gas comes to surface, is possible. In this way, we are able to understand, what share of the available budget do we consume and if this is sufficient to enable the temperature limit below the suggested thresholds.

Hubert's methodology has undergone some criticism as it assumes production fits a simple mathematical form and does not take into account the effects of technological change and political decisions. Also, it provides a forecast for only one peak of production, which might not be true in all countries, as there are nations with huge reserves and may present several peaks over time [12]. The overall objective of Hubbert's peak theory was to use historical data and determine the peak year and future trends [13].

\section{Methodology}

Hubbert first used the logistic function to provide a calibration to empirical data and define the cumulative extraction from an oil field [16]. In this paper, the logistic function is used to fit past data of natural gas production of the top ten producers worldwide. The cumulative production is given by:

$$
P=\frac{K P_{0}}{\left(K-P_{0}\right) e^{-r\left(t-t_{0}\right)}+P_{0}}
$$

where $P$ is the estimated production, $K$ is the proven natural gas reserves, and $P_{0}$ stands for the cumulative production at the reference time, $\mathrm{t}_{0}$. The unconstrained growth rate of production is represented by $r$.

The first derivative of the equation, which represents the rate of production, produced a bell-shaped curve:

$$
\frac{d P}{d t}=\frac{K P_{0} r\left(P_{0}-K\right) e^{-r\left(t-t_{0}\right)}}{\left(\left(P_{0}-K\right) e^{-r\left(t-t_{0}\right)}+K\right)^{2}}
$$

The factors affecting the shape of this curve, are $K$ (proven reserves) and $r$ (growth rate of production) and defined by:

$$
g=\frac{1}{P} \frac{d P}{d t}=r\left(1-\frac{P}{K}\right)
$$

Were $g$ is the cumulative growth rate. Such a method is not always the best fit choice for natural gas production for reasons explained in the next chapter. For the calculation of emissions, the emission factors taken from the literature, are used [15]. For natural gas the values are $56100 \mathrm{~kg} \mathrm{CO}_{2}$ per TJ or 2.35 tons of $\mathrm{CO}_{2}$ per ton of oil equivalent of primary energy. To estimate the emissions, we assume pure methane combustion:

$$
\mathrm{CH}_{4}+2 \mathrm{O}_{2} \rightarrow \mathrm{CO}_{2}+2 \mathrm{H}_{2} \mathrm{O}
$$

Several assumptions were made to conduct the calculations on production and emissions projection. For the emissions calculation, $1 \mathrm{~mol}$ of $\mathrm{CH}_{4}$ produces $1 \mathrm{~mol}$ of $\mathrm{CO}_{2}$ under full stoichiometric combustion. The heating value of

$\mathrm{CH}_{4}$ is considered around $50 \frac{\mathrm{MJ}}{\mathrm{kg}}$ while the efficiency of a conventional combined cycle natural gas power plant is around $55 \%$. For the production projections, only current technologies are taken into account and current recoverable reserves are those have been estimated and published in international literature.

\section{Results \& Discussion}

The top ten producers of natural gas are USA, Russia, Iran, Canada, Qatar, China, Norway, Australia, Saudi Arabia and Algeria. Together they account for more than $85 \%$ of worldwide production, with the latter, exceeding 2800 billion cubic meters in 2018. In Figures 1 and 2, Eq. (2) was used to fit past production data and use this to project to the future. 


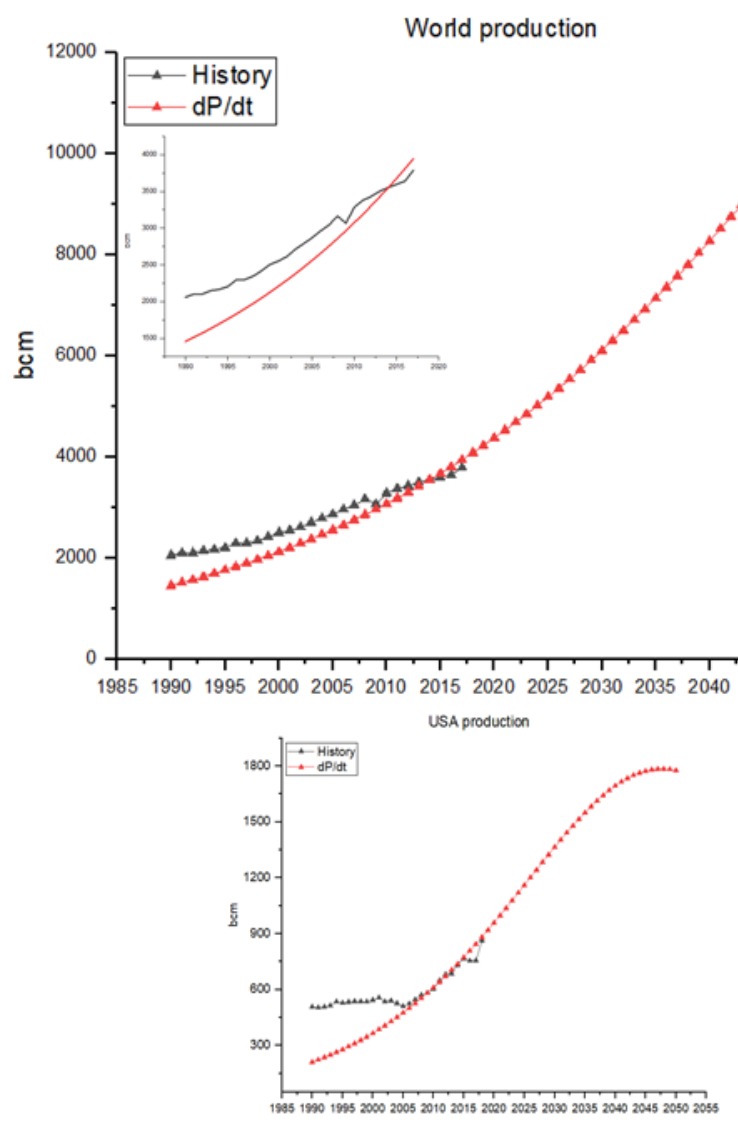

(a)

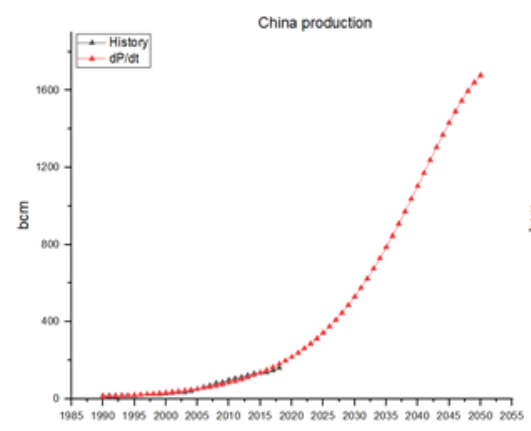

(d)

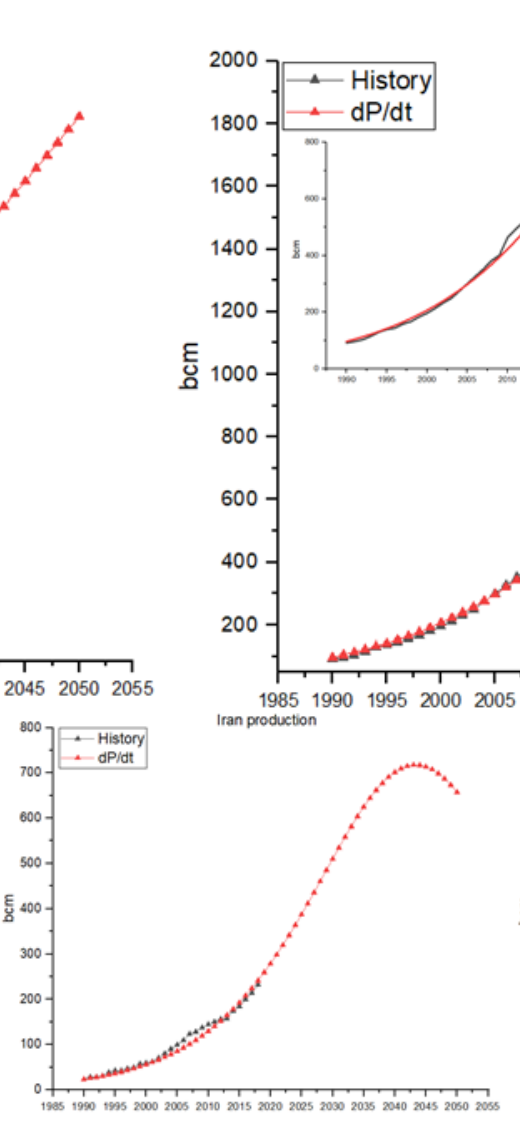

(b)

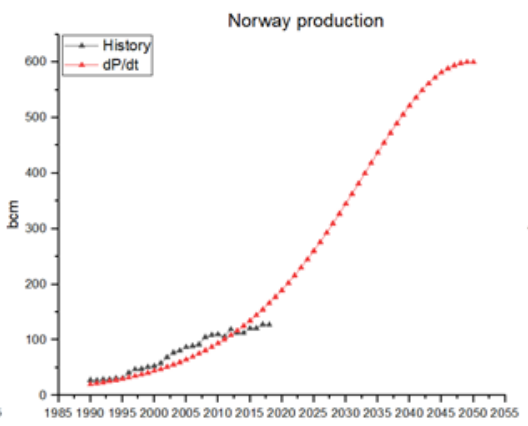

(e)
Middle East production

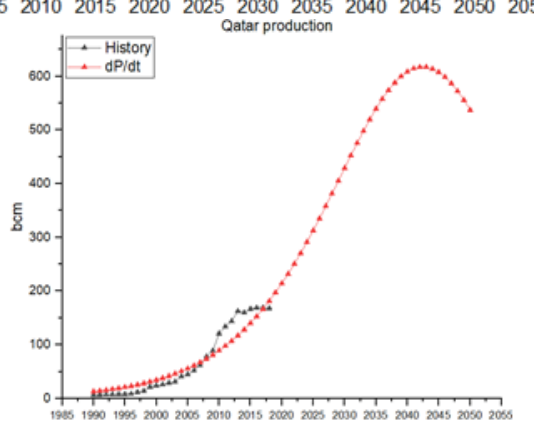

(c)

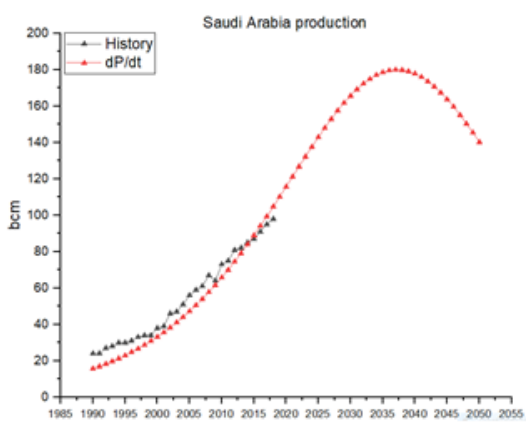

(f)

Figure 1. Natural gas production or different countries-regions. Top left is world production, while on the right is Middle East production. (a) corresponds to USA production, (b) is Iran, (c) Qatar, (d) is China, (e) Norway and (f) refers to Saudi Arabia. Among those countries, Hubbert curve, presents a good fit on the production history. Source of data: data.un.org. 

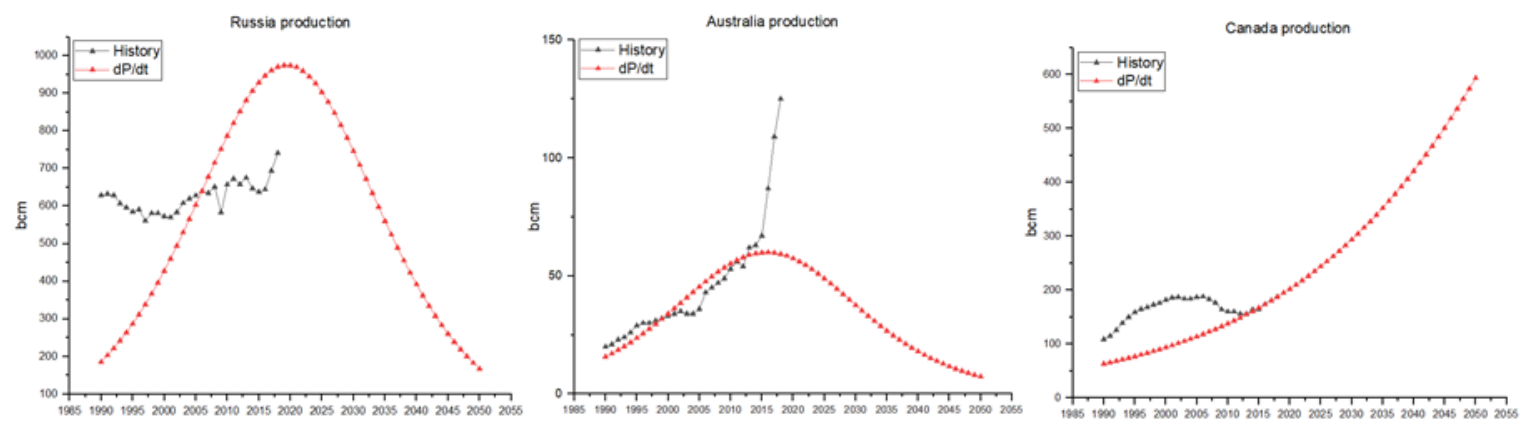

(a)

(b)

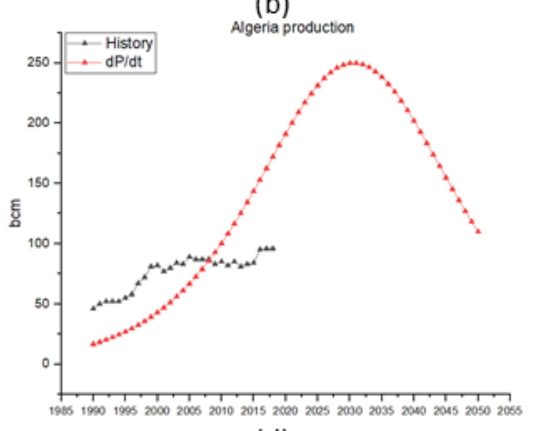

(d)

(c)

Figure 2. Countries that, for various reasons, Hubbert curve doesn't fit well the historical production data of natural gas. (a) is Russia, (b) Australia, (c) Canada, (d) Algeria.

According to the results presented in Figure.1, the Hubbert curve presents a good fit to several countries that are considered among the greatest producers worldwide. In addition to that, we are able to estimate the peak production (Hubbert peaks) given the growth rate of production in each country. This is calculated for each country separately and enables a good estimation of the available reserves, without conducting geological research. In the past years, though, Hubbert analysis, has been criticized due to its failure to accurately predict the oil production reserves in the US. Recent shale oil discoveries along with technological progress that enabled their exploitation boosted the production is a way that couldn't have been predicted several years ago [18]. It is true that the Hubbert analysis doesn't consider technological change or political decisions, which are exogenous factors, to the predictions. This is the reason that the countries studied and presented in Fig. 2, present significant errors in the logistic function fit. Countries such as Russia and Canada, have decided to keep a stable production through years, while Australia has recently discovered vast reserves that have boosted its production. Therefore, those countries do not comply with Hubbert assumptions. In this study the countries that present significant errors under the logistic function curve fit will be excluded from further investigation of emissions and available carbon budget projections. 

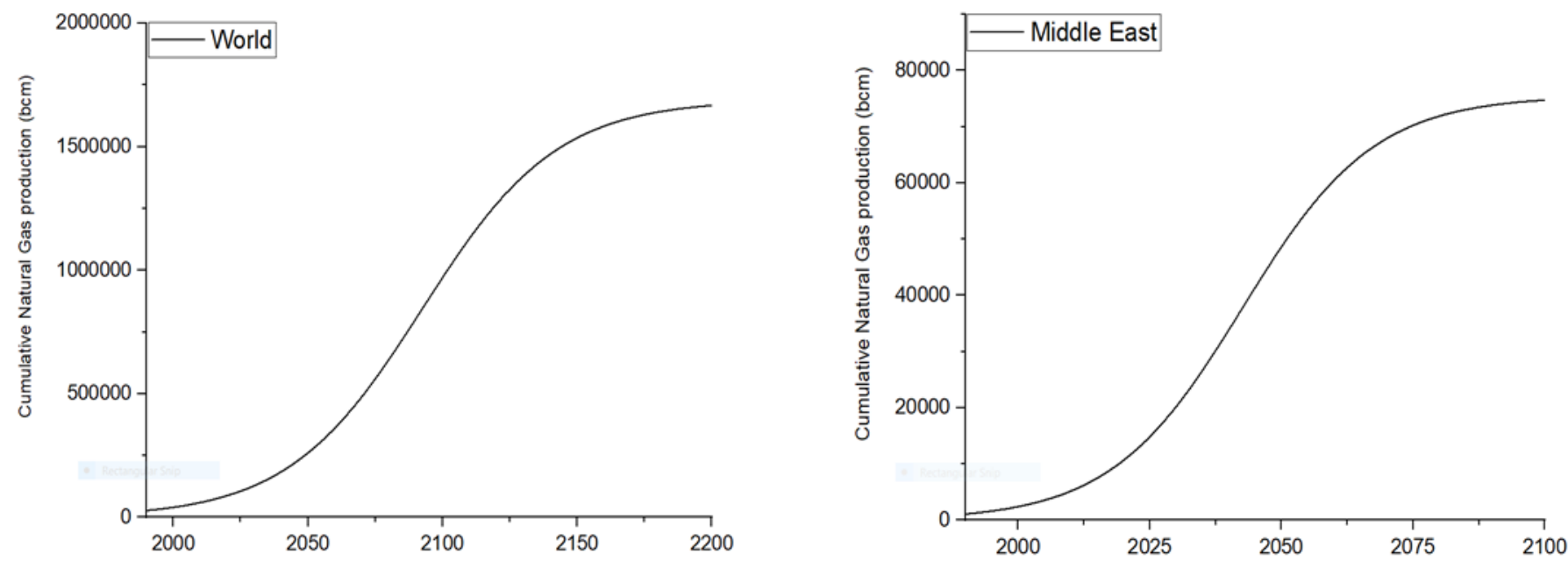

Figure 3. Cumulative natural gas production worldwide and Middle East regions. For the world production we expect a maximum of $1670000 \mathrm{bcm}$ while for Middle East region around $75500 \mathrm{bcm}$. The above curves were calculated using Eq.(1) using data for the available reserves.

To conduct a proper study on emissions calculation and projections, the countries that fall under the Hubbert curve should be considered. To properly determine the error, we use the root-mean-squared values and we calculate the Pearson product coefficient.

Table 2. Summary of fit statistics of cumulative natural gas production in countries and regions studied.

\begin{tabular}{ll}
\hline Country-Region & $\mathbf{R}^{\mathbf{2}}$ \\
\hline World & 0.9908 \\
Middle East & 0.9881 \\
\hline Saudi Arabia & 0.9874 \\
Iran & 0.9837 \\
China & 0.9735 \\
Qatar & 0.9430 \\
Norway & 0.8881 \\
USA & 0.8294 \\
Algeria & 0.6132 \\
Australia & 0.6127 \\
Russia & 0.4734 \\
Canada & 0.1913
\end{tabular}




\section{Emissions}

For the selected countries and using the production projections of Hubbert's logistic function, a study on $\mathrm{CO}_{2}$ emissions was conducted to determine if the projected values fall within the carbon budget limit of $2{ }^{\circ} \mathrm{C}$ and $1.5^{\circ} \mathrm{C}$ as those where stated by International Energy Agency and the IPCC [17].
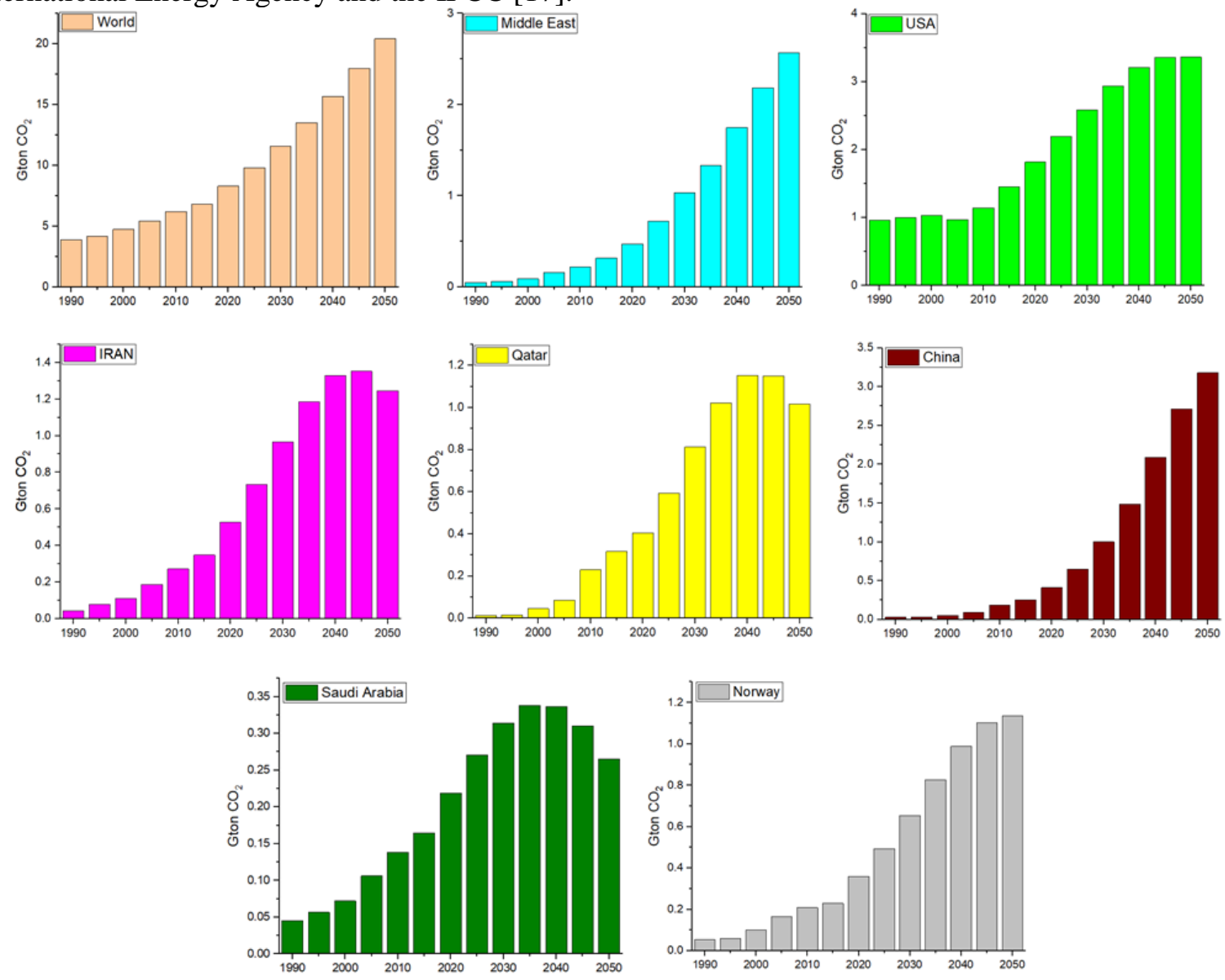

Figure 5. $\mathrm{CO}_{2}$ emissions, as those were estimated using the results of Hubbert's function for the selected countries.

The countries examined, are among the top ten producers of natural gas worldwide. The $\mathrm{CO}_{2}$ emissions are expected to grow constantly until 2050, while the peak is expected to be reached around 2080. The situation differs widely among the reference countries. Iran and Qatar, are expected to reach a peak in their emissions between 2040 and 2050, with Saudi Arabia reaching maximum production a decade earlier. US and Norway present a stabilization of their emissions after 2040 while for China and the Middle East $\mathrm{CO}_{2}$ emissions are expected to grow, mainly due to increased demand in energy for industrial and transportation sectors. Mitigating the effects of this rise on emissions, carbon capture techniques make real sense in order to avoid reaching the carbon budget limits. 
Table.3 Summary of natural gas peak production, peak emissions and estimated year of peak of reference countries.

\begin{tabular}{llll}
\hline Country & $\begin{array}{l}\text { Peak production at } \\
\text { peak year }(\mathbf{b c m})\end{array}$ & $\begin{array}{l}\mathbf{C O}_{\mathbf{2}} \text { emissions at peak } \\
\left.\text { year (Gtonne } \mathbf{C O}_{2}\right)\end{array}$ & Peak year \\
\hline Saudi Arabia & 180.0 & 0.34 & 2037 \\
Iran & 717.6 & 1.35 & 2043 \\
China & 1678.1 & 3.17 & $>2050$ \\
Qatar & 617.2 & 1.16 & 2043 \\
Norway & 599.8 & 1.13 & 2049 \\
USA & 1784.8 & 3.38 & 2048
\end{tabular}
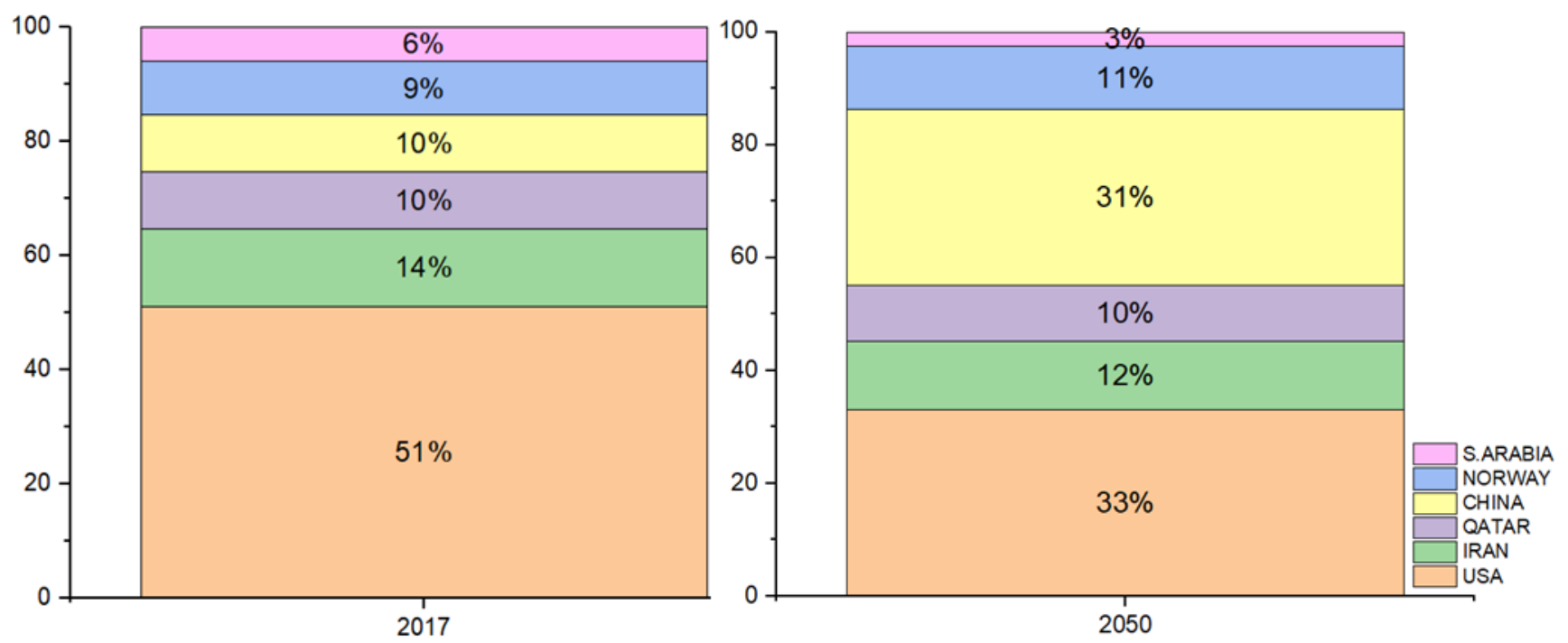

Figure.6 Share of emissions between the selected countries in 2017 and 2050.

As demonstrated in Figure.6, USA, dominates the $\mathrm{CO}_{2}$ emissions between the reference countries, in 2017, with the rest of the countries sharing approximately the same amount. The situation is different in 2050, with China, almost taking the lead, as growth in economic and industrial level, is expected to continue. It is remarkable to mention that Saudi Arabia, by 2050, has entered the declining part of the curve, so its emissions have diminished. It is vital though to determine, what percentage of those emissions, comparing to the worldwide ones. As reported in Figure.7, reference countries account for $59 \%$ of the world ones, while the rest producers, cover the remaining $31 \%$. Those emissions are the cumulative ones between the 2017-2050 period. 


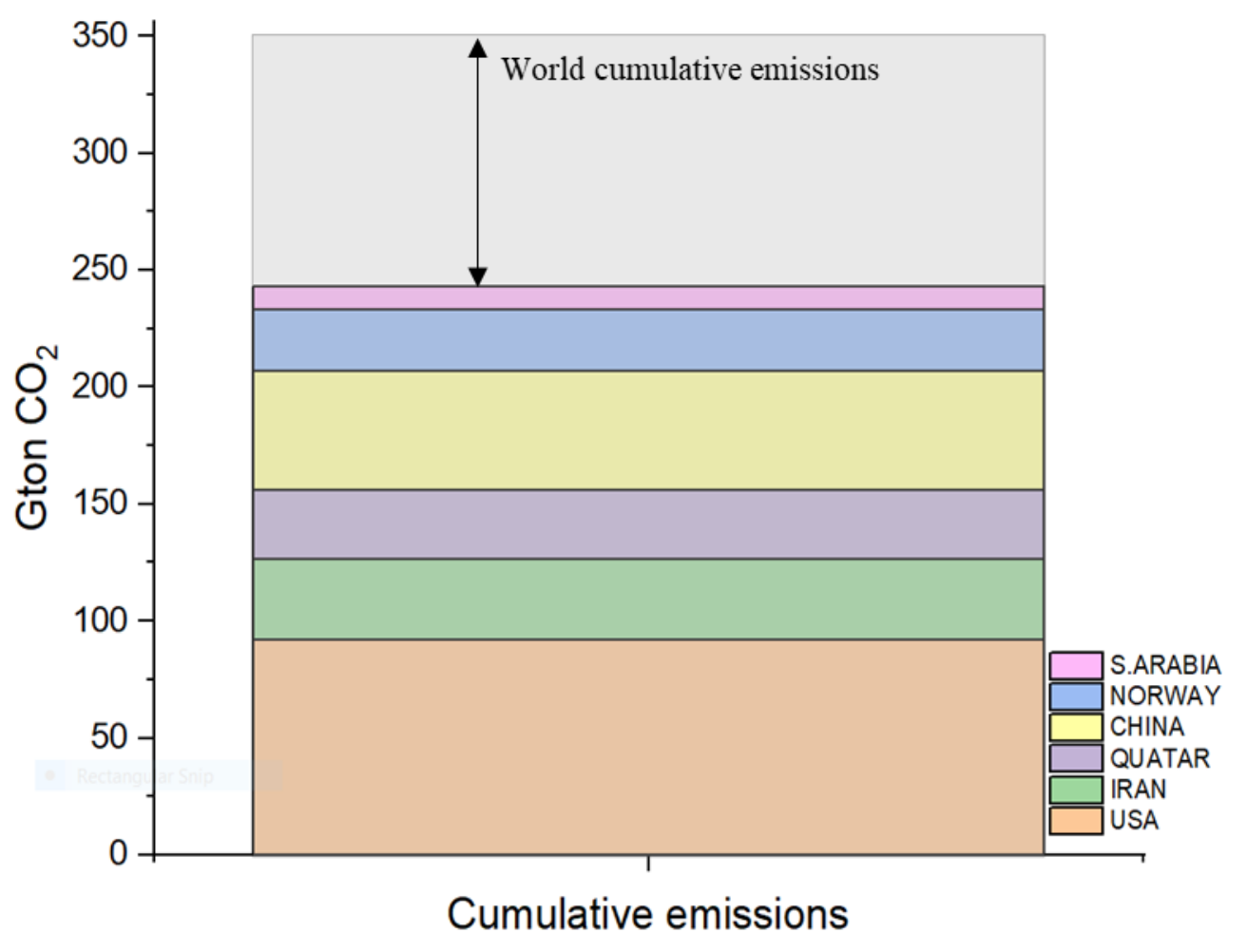

Figure.7 Cumulative emissions from 2017 to 2050 from reference countries and worldwide.

Being aware of the share of the reference countries in the total emissions, the available carbon budget, after the natural gas production, is estimated. The carbon budget differs among the different scenarios of IPCC about the temperature increase. Both scenarios are presented in Table.4. A $1.5{ }^{\circ} \mathrm{C}$ temperature increase is much more desired than a $2{ }^{\circ} \mathrm{C}$ one or greater, for several environmental and socioeconomic reasons. In the first case, only 420 Gtonne $\mathrm{CO}_{2}$ are available to emit, while in 2 ${ }^{\circ} \mathrm{C}$ case the amount increases to 1170 Gtonne $\mathrm{CO}_{2}$.

Table.4 Available carbon budget under IPCC suggested temperature increase.

\begin{tabular}{ccc}
\hline Scenario & Carbon Budget $\left(\right.$ Gtonne $\left.\mathrm{CO}_{2}\right)$ & Reference \\
\hline $1.5^{\circ} \mathrm{C}$ & 420 & {$[5]$} \\
$2.0^{\circ} \mathrm{C}$ & 1170 & {$[5]$}
\end{tabular}




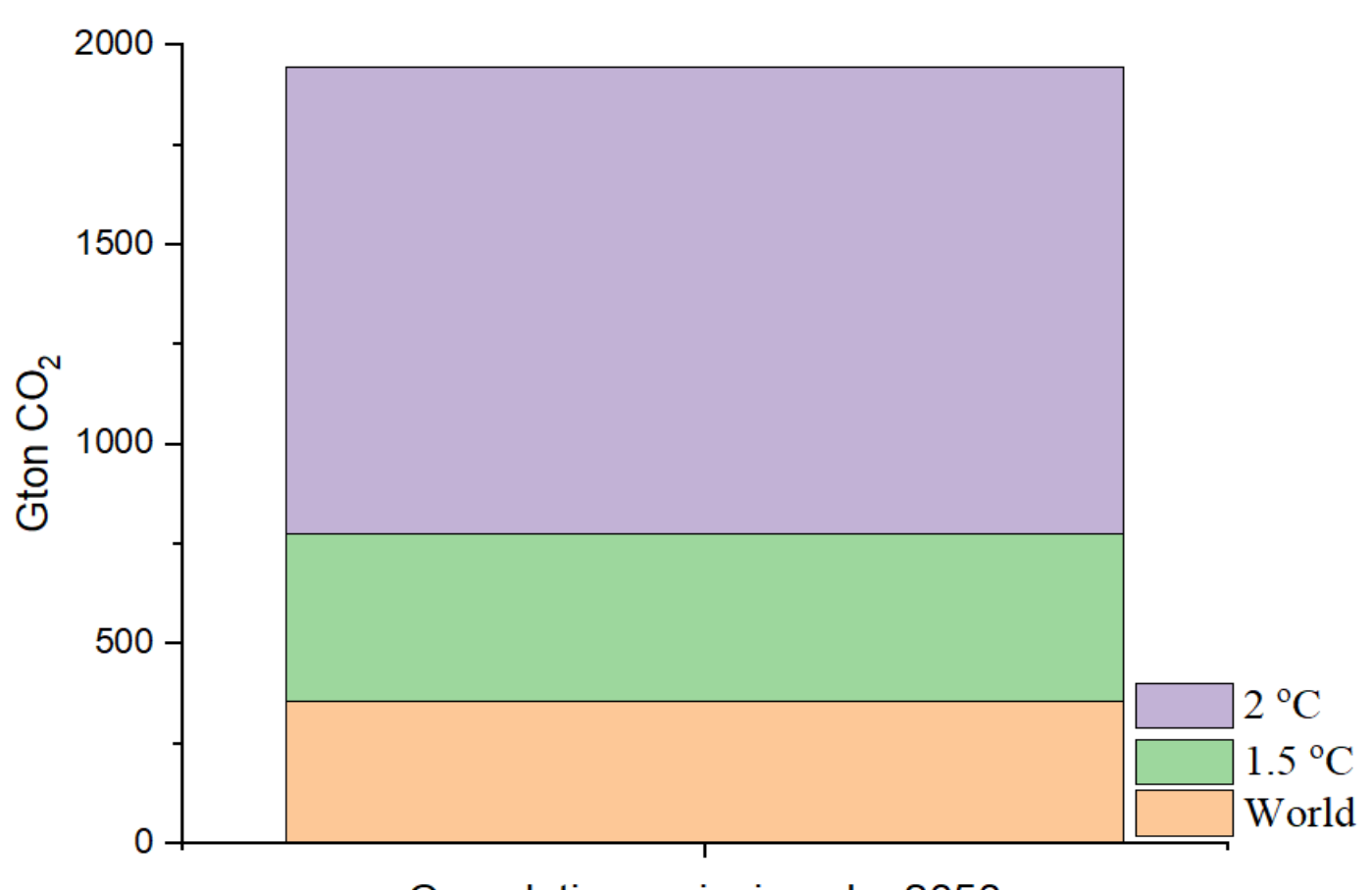

Cumulative emissions by 2050

Figure. 8 Cumulative emissions by 2050 under the carbon budget available, under the two scenarios.

As presented in Figure.8, natural gas $\mathrm{CO}_{2}$ emissions in a world level, by 2050 account for $356 \mathrm{Gt}$ that are approximately $85 \%$ of the available carbon budget for the $1.5{ }^{\circ} \mathrm{C}$ scenario and around $30 \%$ of the $2.0{ }^{\circ} \mathrm{C}$ scenario. Especially, when it comes to the first case, with only natural gas emissions almost consuming two thirds of the budget, if we consider other fossil fuels, an extended overshoot of the limits is expected. To avoid such case, carbon capture, replacement of old power plants with more efficient ones and extensive after treatment of flue gases is essential. Even in the $2.0^{\circ} \mathrm{C}$ case, the "Business as usual" is not sufficient to stay within IPCCs limits and other strategies focusing on sustainable development are vital.

\section{Conclusions}

The aim of this paper, was the estimation of gas production projections of major gas-producing nations and use these values to determine the emissions and eventually the consumption of the available carbon budget according to the values given by the IPCC. Using Hubbert's bell-shaped logistic function, fitting with adequate error values was possible for most of the countries selected. As production of natural gas is among others, a political decision in many cases, countries do not exploit their full gas-potential. In some other nations studied, recently discovered fields, that are included in the nations reservoirs, are not yet produced. Such cases present significant standard deviation error and are excluded from the analysis. For the rest, after projecting the production, the emissions were estimated using the standardized emission factors. The analysed countries account for, almost, $60 \%$ of world emissions in 2017. The results predict that major growth in emissions is expected from China, while the USA is projected to be among the greatest emitters. By 2050 the available carbon budget accounts for $356 \mathrm{Gt} \mathrm{CO}_{2}$ in the case of the $1.5^{\circ} \mathrm{C}$ scenario. If the production continues unconstrained and without mitigation actions, only natural gas production is expected to consume $85 \%$ of this budget, leaving hardly any space for other production of fuels and minerals. 


\section{References}

[1] IEA (2019), Natural Gas Information 2019, IEA, Paris https://www.iea.org/reports/natural-gas-information-2019

[2] Niek Mouter, Auke de Geest, Neelke Doorn, A values-based approach to energy controversies: Value-sensitive design applied to the Groningen gas controversy in the Netherlands, Energy Policy, Vol 122, pp 639-648, 2018

[3] Andrew Burnham, Jeongwoo Han, Corrie E. Clark, Michael Wang, Jennifer B. Dunn, Ignasi Palou-Rivera. Life-Cycle Greenhouse Gas Emissions of Shale Gas, Natural Gas, Coal, and Petroleum. Environ. Sci. Technology, Vol 46, pp 619627,2012

[4] UNFCCC, 2015. Synthesis report on the aggregate effect of the intended nationally determined contributions. Available at: https://unfccc.int/sites/default/files/resource/docs/2015/cop21/eng/10a01.pdf

[5] Global Carbon Budget 2015, C. Le Quéré , R. Moriarty , R. M. Andrew , J. G. Canadell , S. Sitch , J. I. Korsbakken , P. Friedlingstein , G. P. Peters , R. J. Andres , T. A. Boden, R. A. Houghton , J. I. House , R. F. Keeling, P. Tans, A. Arneth, D. C. E. Bakker, L. Barbero, L. Bopp, J. Chang, F. Chevallier, L. P. Chini, P. Ciais, M. Fader, R. A. Feely, T. Gkritzalis, I. Harris , J. Hauck, T. Ilyina, A. K. Jain, E. Kato, V. Kitidis, K. Klein Goldewijk, C. Koven, P. Landschützer, S. K. Lauvset, N. Lefèvre, A. Lenton, I. D. Lima32, N. Metzl, F. Millero , D. R. Munro, A. Murata, J. E. M. S. Nabel, S. Nakaoka, Y. Nojiri, K. O’Brien, A. Olsen , T. Ono, F. F. Pérez, B. Pfeil, D. Pierrot, B. Poulter, G. Rehder, C. Rödenbeck, S. Saito, U. Schuster, J. Schwinger, R. Séférian, T. Steinhoff, B. D. Stocker, A. J. Sutton, T. Takahashi, B. Tilbrook, I. T. van der Laan-Luijkx , G. R. van der Werf, S. van Heuven, D. Vandemark, N. Viovy, A. Wiltshire, S. Zaehle, N. Zeng, Earth Syst. Sci. Data, 7, 349-396, 2015 doi:10.5194/essd-7-349-2015

[6] IPCC Special Report on Renewable Energy Sources and Climate Change Mitigation, 2016 https://www.uncclearn.org/sites/default/files/inventory/ipcc15.pdf

[7] Kamia Handayania, Tatiana Filatova, Yoram Krozera, Pinto Anugrah, Seeking for a climate change mitigation and adaptation nexus: Analysis of a long-term power system expansion. Applied Energy, Vol 262, 2020

[8] Hultman, N., Rebois, D., Scholten, M. \& Ramig, C. The greenhouse impact of unconventional gas for electricity generation. Environ. Res. Lett. 6, 2011

[9] Moniz, E. J., Jacobi, D.H., Meggs, J. A. The Future of Natural Gas: An Interdisciplinary MIT Study (MIT, 2011); https://energy.mit.edu/wp-content/uploads/2011/06/MITEI-The-Future-of-Natural-Gas.pdf

[10] Howarth, R. W., Santoro, R. \& Ingraffea, A. Methane and the greenhouse-gas footprint of natural gas from shale formations. Clim. Change 106, pp 679-690, 2011

[11] Haewon McJeon, Jae Edmonds, Nico Bauer, Leon Clarke, Brian Fisher, Brian P. Flannery, Jérôme Hilaire, Volker Krey, Giacomo Marangoni, Raymond Mi, Keywan Riahi, Holger Rogner, Massimo Tavoni. Limited impact on decadal-scale climate change from increased use of natural gas. Nature, vol. 514, pages482-485, 2014

[12] G.Maggio, G.Cacciola A variant of the Hubbert curve for world oil production forecasts, Energy Policy Volume 37, Issue 11, Pages 4761-4770, 2009

[13] Hubbert, M.K., 1956. Nuclear Energy and the Fossil Fuels, American Petroleum Institute, Drilling and Production Practice. In: Proceedings of Spring Meeting. San Antonio, Texas, pp. 7-25.

[14] Panagiotis Fragkos, Kostas Fragkiadakis, Leonidas Paroussos, Roberta Pierfederici, Saritha S. Vishwanathan, Alexandre C. Köberle, Gokul Iyer, Chen-Min He, Ken Oshiro, Coupling national and global models to explore policy impacts of NDCs, Energy Policy, pp. 462-473, 2018

[15] Eggleston H.S., Buendia L., Miwa K., Ngara T., and Tanabe K. 2006 IPCC Guidelines for National Greenhouse Gas Inventories, Prepared by the National Greenhouse Gas Inventories Programme,. Japan : IGES, 2006

[16] Hubbert, M.K., 1962. Energy Resources, A report to the Committee on Natural Resources: National Academy of Sciences. vol. 54. National Research Council Publication, 1000-D, Washington, DC, pp. 61-67.

[17] IPCC, 2018: Summary for Policymakers. In: Global Warming of $1.5^{\circ}$ C. An IPCC Special Report on the impacts of global warming of $1.5^{\circ} \mathrm{C}$ above pre-industrial levels and related global greenhouse gas emission pathways, in the context of strengthening the global response to the threat of climate change, sustainable development, and efforts to eradicate poverty [Masson-Delmotte, V., P. Zhai, H.-O. Pörtner, D. Roberts, J. Skea, P.R. Shukla, A. Pirani, W. Moufouma-Okia, C. Péan, R. Pidcock, S. Connors, J.B.R. Matthews, Y. Chen, X. Zhou, M.I. Gomis, E. Lonnoy, T. Maycock, M. Tignor, and T. Waterfield (eds.)]. World Meteorological Organization, Geneva, Switzerland, 32 pp.

[18] Sakiru Adebola Solarin, Luis A. Gil-Alana, Carmen Lafuente, An investigation of long range reliance on shale oil and shale gas production in the U.S. market,Energy,Volume 195, 2020 